\title{
The one Period Problem of a Monopoly Incentive Compatible Equity and Debt-linked Contracts JEL:G24, D82
}

\author{
Ayi Ayayi * \\ Finance Department \\ Faculty of Business, Ryerson University \\ and \\ Centre d'Études en Réglementation Économique et Financière \\ 350 Victoria St, Toronto, (Ontario), Canada M5B 2K3 \\ Tel:(416) 979-5000 Ext 6727; Fax:(416) 979-5266, E-mail: aayayi@ryerson.ca
}

January 15, 2003

\begin{abstract}
In this paper, I analyze the role of equity and debt linked contracts in a monopoly setting. I show that the equity contract dominates the debt linked contracts because it attracts higher ability entrepreneurs and provides more profit to the monopolist. I also show that the social welfare that results from the equity contract exceeds those derived from debt financial instruments.
\end{abstract}

*I thank Josh Lerner, Stylianos Perrakis, Michel Poitevin, Michel Patry, Lorne N. Switzer, and Michelle Breton for their insightful and thoughtful comments on the previous version. I am grateful to the participants at the meeting of European Financial Management Association (1999), FMA (2002) AFFI (2002) Portuguese Network (2002) seminar participants at John Molson Business School of Concordia University, HEC of Montreal, Odette Business School of University of Windsor, Business School of University of Regina, and Business School of Memorial University for insightful comments. 


\section{Introduction}

There has been a significant interest in the capital structure since Jensen and Meckling (1976) introduced the incentive argument which claims that firms are run by self interested agents and that the separation of ownership and control gives rise to agency costs. There are many reasons for this, among which the deterrence of a firm and/or an Eneur quality. To overcome these concerns in a competitive economy, second best financial contracts have been proven as good financial schemes to prune out an Eneur. ${ }^{1}$ However, in a world where the capital is controlled by one major financier, screening may not be possible while a socially optimal contract that fulfills the maximization objective of the monopoly could be designed.

In this respect, the paper aims to investigate, under a monopoly regime, what is the optimal financial vehicle that a financier should resort to to nurture his investees and which at the same time is socially optimal. Providing a soundful answer for this question is foremost important for the third world countries that lack a developed financial sector and where the existing financial sector is almost controlled by a state control monopoly financier that take active roles in the development of their countries. It will also be useful for major financial institution like World Bank and the IFM that behave like monopolies in providing funds for the under developed countries to nurture and to sustain their economic and social growth. The result of the paper will also be useful for any one time investor who would like to know the appropriate financial instrument to employ when approached by a prospective Eneur. To delve into the paper objective, I focus on adverse-selection-driven contract because the imperfect monopoly moves first to screen out the Eneur and maximizes his utility while the Eneur is held to a given utility level. ${ }^{2}$

Rather than taking the financial vehicle as given, like in the previous works, I question the appropriateness of the financial instrument that should be used to mitigate the hidden-information problem faced by MI at the outset of this relation with the Eneur. Therefore, gains from improving the contractual relation Ex-ante should accrue primarily to the MI and the incentive to optimize the contract is adverse-selection-driven induced. Moreover, I abstract from stage financing i.e. multi-periods game because my concern is at the beginning $(t=0)$ of the contractual relation instead of the mechanisms to deal with the ex-post agency problems. ${ }^{3}$

The main result of the paper is as follows. In one period monopoly structure, neither equity nor debt-linked contracts are able to sort out the Eneur by his type. However, it is only the equity contract that fulfills the MI's best interest and at the same time is socially optimal.

\footnotetext{
${ }^{1}$ Harris and Raviv(1991,1992) and Tirole (1994) provide interesting surveys of these questions.

${ }^{2}$ Without loss of generality, note that this is one way to justify the principal-agent paradigm I are applying to the MI-Eneur contractual relation.

${ }^{3}$ Hart(1995) and Salanié(1997) can be consulted for multi-periods games
} 
The paper draws upon financial contracting literature, in an attempt to improve the allocation of risky wealth in an incomplete market. Harris and Raviv (1991, 1992) and Tirole (1994) provide interesting surveys that extensively analyze the characteristics of debt contract as a complex relationship between a borrower and a lender. Grossman and Hart(1982) show that the choice of debt is influenced by its incentive effect as well as the risk that the manager will have to carry. The key point in Grossman and Hart (1982) is that since the manager has to bear bankruptcy costs, debt acts as a bond which the Eneur posts to assure equity holders that their funds will not be completely misappropriated. Jensen (1986) argues that debt financing reduces managerial incentives to misallocate funds because its commits management to return cash to the capital market. Myerson (1979), Bester (1985), Freixas and Laffont (1990), Besanko and Thakor (1987), and Webb (1991) examine how some flexibility can be introduced in debt contracts by offering to the borrowers a whole menu of contracts with different provisions.

Departing from Leland and Pyle (1977), several papers among others(Amit, Glosten and Muller (1990), Admati and Pfleiderer (1994), Fluck (1998) have noted that a higher entrepreneurial share signal a higher project value. Myers and Majluf (1984) in a same line like Leland and Pyle (1977) contend that because of adverse selection, there are severe problems in raising outside equity and just as in Akerlof (1970), adverse selection will preclude any trade except in the lowest value state. They show that debt financing is preferred to equity even when debt is not riskless.

As for convertible debt mechanisms, Barnea, Haugen and Senbet (1985) show that they ease the resolution of complex agency problems that remain unresolved through the market place because of the call or the put characteristics that are embedded in convertible debts. Bergemann and Hege (1998) derive the optimal convertible debt contract that induces an Eneur with the right incentives for the allocation of funds. Rupullo and Suarez (1998), Casamatta (1999) as well as Schmidt (2000), in a model in which the incentive problem is double sides, show that convertible debt can force the contractual parties to invest efficiently. Bacha and Walz(2001) demonstrate that with convertible security, the ex-ante agreed optimal exit policy among the different classes of the shareholders can be implemented.

The paper is structured as follows. The general setup of the model appears in Section II. The design of the different financial contracts is taken up in Section III where the choice of the optimal contracting capital structure is derived. In Section IV, I provide the welfare analysis of the incomplete financial contracts to find the best financial contract from the social view. Section V concludes. The graph of the optimal contract and all proofs appear in the Appendix. 


\section{The General Setup of the Model}

\section{A Sequence of Actions and Events in the Game}

The game I design is a one-period game in incomplete information under uncertainty. Our concern is on the beginning of the first period i.e. $t=0$. Therefore, I abstract from the MI multiple stages investment (there are several papers that study stage financing) to alleviate the ex-post agency problems. Rather, I concentrated on the critical adverse selection problem that the MI tend to resolve at the outset of the first stage financing. In the game, there are three steps with the following sequence of moves. In step one, the uninformed MI offers an incentive scheme to the Eneur. In step two, the Eneur accepts or rejects the incentive scheme. If he rejects the contract, he gets his reservation utility. In step three, the Eneur who subscribes to the incentive scheme plays the game stipulated by the mechanism.

\section{B Endowments, Preferences, Time Horizon, and Investment}

The economy I consider has two dates indexed by $t=0,1$ and two agents. The agents are the MI and the Eneur. Following the principal-agent literature, I assume that the MI, who acts as a principal, is risk neutral. As for the Eneur, who acts as the agent, rather than assuming he is risk-averse I assume that his is risk neutral because my concern is not aimed at improving the allocation of risky wealth in an incomplete market and having profound effects on Eneurial Ex-post behavior. Therefore, my approach differs significantly. Instead, it is intended to maximizes the informativeness of the financial instrument contract chosen by the Eneur by "eventually" revealing his ability and by allowing the MI to realize the highest expected profit as possible.

At date $\mathrm{t}=0$, the Eneur has access to a risky project that yields a random pay-off at $t=1$, if it is undertaken. A fixed investment of $\$ K$ is required to activate the project. Due to personal wealth constraints, the Eneur approaches the MI to raise $\$ \mathrm{~K}$. The Eneur may have assets in place but, since they play no role in activating the project,I assume that they are worthless.

\section{Information Structure and the Eneur Characteristics}

At $\mathrm{t}=0$, I assume that two types of observationally identical Eneurs exist: high-ability and low-ability Eneurs. I denote the Eneur's type by $\mathrm{i} \in\{\mathrm{H}, \mathrm{L}\}$. The Eneur knows his type but the MI does not. At $\mathrm{t}=0$, if the Eneur undertakes his risky project, then at $\mathrm{t}=1$, it yields a return of $X_{1}$ with probability (w.p.) $\theta_{i} \in\left(\begin{array}{ll}0 & 1\end{array}\right)$ and $X_{2}$ w.p. $\left(1-\theta_{i}\right)$. A realization of $X_{1}$ will be referred to as project success and a realization of $X_{2}$ will 
be termed as project failure such as $0<X_{2}<K<X_{1}$. Let $\theta_{H}>\theta_{L}$ so that the high-ability Eneur has a higher probability than the low-ability Eneur of realizing $X_{1}$. There exists in the economy high-ability Eneurs in measure $\eta$ with $0<\eta<1$ and low-ability Eneurs in a proportion of $(1-\eta)^{4}$. Moreover, because of the higher failure rate of new ventures stemming form the Eneurs' lack management skills (Gorman and Sahlman(1989), Timmons (1994)), I hypothesize that $0<\eta<(1-\eta)$.

Further, I hypothesize that both types of Eneur can engage in another job market and earn $\psi_{i}>0 . \psi_{i}$ represents the H-type and L-type Eneurs' opportunity cost if they do not engage in an alternative labor market. I denote the level of utility associated to $\psi$, the reservation utility. For simplicity, I normalize the Eneur's outside opportunity level of utility to $\psi_{i}$.

\section{The Types of Contracts}

Given the required fixed's investment $\$ \mathrm{~K}$ to activate the venture, the MI, ex-ante, is looking for the optimal financial contract. To achieve this objective, I compute the optimal contract that stems from the equity and the debt-link securities to finance the venture, and then compare the optimal results among them to find the optimal contract.

In each contract, the MI's expected profit consists of what is left over from what he receives in each contract and from what he gives to the Eneur. Each contract proposed by the MI satisfies the high-ability and low-ability individual's rationality constraints in order to be sure that both types of Eneur would participate. Moreover, to avoid the misrepresentation of the Eneur, the proposed policy by the MI must also satisfy the incentive-compatibility constraints. Thus, the MI must restrict his attention to the menu that induces the Eneur to truthfully reveal his type. Therefore, the MI's optimization problem is to find his optimal policy in each type of contract by maximizing his expected profit, subject to both incentives-compatibility constraints and participation constraints.

\section{A Equity Contract}

I assume that the equity contract is a proportion $\phi_{i}$ of the venture value $V_{i}=\theta_{i} X_{1}+$ $\left(1-\theta_{i}\right) X_{2}$ received by the MI from high ability Eneur or from the low ability Eneur for the fixed investment amount of $\$ \mathrm{~K}$. In this contract, the MI's profit is given by equation (1). Inequality (2) and inequality (3) are the high-ability and the low-ability Eneurs' self-selection constraints. Together, both inequalities point to the following conclusion: telling truth is better than lying. The inequality (4) and the inequality (5) are the

\footnotetext{
${ }^{4}$ Note that while we do know that there exists high and low ability Eneur we don't know the true number corresponding to each class of Eneur
} 
participation constraints of both types of Eneurs . They must be satisfied otherwise the Eneurs will not undertake the project. Therefore, the optimization of the objective function requires that the MI maximizes his profit, subject to both types of Eneur's incentive-compatibility constraints and participation constraints.

$$
M A X \Pi_{\left(\phi_{i}\right)}=\eta\left(\phi_{H} V_{H}-K\right)+(1-\eta)\left(\phi_{L} V_{L}-K\right)
$$

subject to:

$$
\begin{aligned}
\left(1-\phi_{H}\right) V_{H} & \geq\left(1-\phi_{L}\right) V_{H} \\
\left(1-\phi_{L}\right) V_{L} & \geq\left(1-\phi_{H}\right) V_{L} \\
\left(1-\phi_{H}\right) V_{H}-\psi_{H} & \geq 0 \\
\left(1-\phi_{L}\right) V_{L}-\psi_{L} & \geq 0
\end{aligned}
$$

In solving the MI optimization program for the equity contract, I obtained the optimal equity contract stated in the following proposition.

\section{$\underline{\text { Proposition I }}$}

Under the equity contract, the optimal policy i.e. the the proportion of the venture received by the MI and its corresponding profit denoted by the asterisks is given by:

$$
\begin{gathered}
\phi_{P E}^{*}=1-\frac{\psi_{L}}{V_{L}} \\
\Pi_{P E}^{*}=\eta\left[V_{H}-V_{L}-\psi_{L}\left(\frac{V_{H}}{V_{L}}-1\right)\right]+\left(V_{L}-\psi_{L}-K\right)
\end{gathered}
$$

Proof: see Appendix

$\phi_{P E}^{*}$ is the pooling proportion of the venture's equity that is given up by the Eneur. It is obtained by maximizing equation (1), subject to inequality (2), to inequality (5). $\Pi_{P E}^{*}$ is the corresponding profit to $\phi_{P E}^{*}$. First, from proposition I, it follows that, if the venture capitalist uses an equity device to separate the high-ability Eneur from the low-ability Eneur, he will achieve a pooling result. Moreover, note that the high-ability Eneur will always prefer to be pooled with the low-ability Eneur because what he gives up in the pooling contract is less than what he will abandon if the MI knows he is a high-ability Eneur i.e. $\phi_{P E}^{*}<\phi_{H}^{*}=1-\frac{\psi_{H}}{V_{H}}$.

\section{B Debt Contract with Collateral}

The debt contract designed by the MI for the high and low ability Eneur consists of the coupon value $\rho_{i}$ if the project returns $X_{1}$ at the end of the period, and $\mathrm{C}+X_{2}$ if it 
returns $X_{2}$, where $\mathrm{C}$ is the value of the collateral. The collateral is an additional asset that the Eneur will lose in the event of default, i.e., when the project returns $X_{2}$. In such case, the Eneur assigns as collateral assets objects that would not ordinarily be lawfully appended. In this respect, I assume that, aside from the transaction costs that the MI will incur to collect the collateral and the liquidating costs of the collateral, the MI and the Eneur could have different opinions or beliefs about C. To capture this disparity, let $\beta$ be the disparity factor of the valuation of $\mathrm{C}$, as in $\operatorname{Baro}(1976)$ such that $\beta C$ represents the MI's valuation of $\mathrm{C}$, with $\beta \in[0,1]$.

A key point regarding $\beta$ is that, depending on its value, i.e, either $\beta \in[0,1[$ or $\beta=1$, the equilibrium that stems from the collateral-debt contract will be different. To take this phenomenon into account, I derive two propositions (proposition II and proposition III) from the collateral debt contract. Before formulating these propositions, let us set the incentive-mechanism design by the MI to the Eneur.

As in the equity contract, the MI's problem is to maximize his profit, subject to the incentive-compatibility constraints and the participation constraints of both types of Eneur.

$$
M A X \Pi_{\left(\rho_{i}, C_{i}\right)}=\eta\left[\theta_{H} \rho_{H}+\left(1-\theta_{H}\right)\left(X_{2}+\beta C_{H}\right)-K\right]+(1-\eta)\left[\theta_{L} \rho_{L}+\left(1-\theta_{L}\right)\left(X_{2}+\beta C_{L}\right)-K\right]
$$

subject to:

$$
\begin{aligned}
\theta_{H}\left(X_{1}-\rho_{H}\right)-\left(1-\theta_{H}\right) C_{H} & \geq \theta_{H}\left(X_{1}-\rho_{L}\right)-\left(1-\theta_{H}\right) C_{L} \\
\theta_{L}\left(X_{1}-\rho_{L}\right)-\left(1-\theta_{L}\right) C_{L} & \geq \theta_{L}\left(X_{1}-\rho_{H}\right)-\left(1-\theta_{L}\right) C_{H} \\
\theta_{H}\left(X_{1}-\rho_{H}\right)-\left(1-\theta_{H}\right) C_{H}-\psi_{H} & \geq 0 \\
\theta_{L}\left(X_{1}-\rho_{L}\right)-\left(1-\theta_{L}\right) C_{L}-\psi_{L} & \geq 0 \\
C_{i} & \geq 0
\end{aligned}
$$

where $\mathrm{i}=\mathrm{H}, \mathrm{L}$.

In this contract, equation (8) represents the venture capitalist's profit. Inequality (9) and inequality (10) stand for the high-ability and the low-ability Eneurs' incentivecompatibility constraints. Their individual participation constraints are given by inequality (11) and inequality (12), respectively. Inequality is the collateral condition

\section{B.1 The disparity factor of the valuation of the collateral: $\beta \in[0 ; 1[$.}

In the following proposition, I show that when $\beta \in[0 ; 1[$, the optimal collateral-debt policy is that of pooling equilibrium. In this pooling equilibrium, the high-ability Eneur 
passes himself off as the low-ability Eneur because what he gives up is less than what he will give up if the MI knows that he has high ability.

\section{Proposition II}

Under the debt contract, when $\beta \in[0 ; 1[$, the MI's optimal credit mechanism (denoted by the asterisks) about the type of Eneur, is the pooling contract, as shown by:

$$
\begin{gathered}
C_{H}^{*}=C_{L}^{*}=0 \quad \rho_{P D}^{*}=X_{1}-\frac{\psi_{L}}{\theta_{L}} \\
\Pi_{P D}^{*}=\eta\left(\theta_{H}-\theta_{L}\right)\left(X_{1}-X_{2}-\frac{\psi_{L}}{\theta_{L}}\right)+\left(V_{L}-\psi_{L}-K\right)
\end{gathered}
$$

Proof: see Appendix

$C_{H}^{*}=C_{L}^{*}$ and $\rho_{P D}^{*}$ are obtained by maximizing equation (11), subject to inequality (12), to inequality (16). $\Pi_{P D}^{*}$ is the corresponding pooling profit to $\rho_{P D}^{*}$, which is the pooling-equilibrium debt coupon.

Contrary to what one might think, i.e., that the collateral-debt contract might separate low-ability from high-ability Eneurs, proposition II shows that when $\beta \in[0 ; 1[$, the collateral-debt contract does not allow the MI to solve the adverse-selection problem he faces at the outset of his relation with the Eneur. A remarkable attribute of the optimal collateral-debt scheme, when $\beta \in[0 ; 1[$, is that the collateral of each Eneur type is zero. Nevertheless, one might think that collateral would be an efficient filtering mechanism. The intuition behind this result is that, as a monopolist, the MI's objective is to extract maximum rent from the project rather than rely on the collateral in case of default, as is the case in the competition models.

So technically, why not sort Eneurs by offering a lower coupon rate to Eneurs who give more collateral? The reason is that, by starting from the full-information solution, the MI may simultaneously raise the collateral and lower the coupon rate for the lowability Eneur; thus the high-ability Eneur would have even more incentive to choose the low-ability Eneur contract instead of the high-ability Eneur contract. The moral behind this argument is that the high-ability Eneur really likes the lower coupon rate but is not as concerned about the higher collateral requirement because his probability of failure is low. In this respect, collateral is not an efficient sorting mechanism and is optimally set as equal to zero. This finding contradicts the general view that claims that collaterized debt alleviates the asymmetrical-information problems between investors and Eneurs because it reduces investors' welfare loss in case of bankruptcy. As a result, when $\beta \in$ $[0 ; 1[$, one cannot follow the general wisdom of raising the collateral and lowering the interest rate for the high-ability Eneur, and doing the opposite for the low-ability Eneur in order to separate them. 


\section{B.2 The disparity factor of the valuation of the collateral: $\beta=1$.}

Turning to the case where $\beta=1$, I derive the next proposition that claims that the MI is able to distinguish the Eneurs' abilities by using the collateral-debt contract.

\section{Proposition III}

For $\beta=1$, the optimal debt-incentive mechanism that allows the MI to separate the high-ability Eneur from the low-ability Eneur is given by:

$$
\begin{array}{cc}
C_{L}^{*}=0 ; & C_{H}^{*}>0 \\
\rho_{L}^{*}=X_{1}-\frac{\psi}{\theta_{L}} ; & \rho_{H}^{*}=\rho_{L}^{*}-\frac{1-\theta_{H}}{\theta_{H}} C_{H}^{*} \\
\Pi_{S D}^{*}=\eta\left[\left(\theta_{H}-\theta_{L}\right)\left(X_{1}-X_{2}-\frac{\psi_{L}}{\theta_{L}}\right)-2\left(1-\theta_{H}\right) C_{H}^{*}\right]+\left(V_{L}-\psi_{L}-K\right)
\end{array}
$$

where $\Pi_{S D}^{*}$ stands for the separating-equilibrium profit that results from the collateraldebt contract.

Proof: see Appendix

From proposition III, it follows that, while the coupon contained in the high-ability Eneur contract is less than the coupon embodied in the low-ability Eneur incentive scheme, the relationship between their collateral is the opposite. An interesting attribute of proposition III is that the collateral of the high-ability Eneur is not only greater than zero but a decreasing function of the coupon. This relation, which does not exist in the low-ability Eneur contract, clearly shows that the high-ability Eneur enjoys having a low coupon because he knows he has the necessary dexterity to succeed in his project. For the low-ability Eneur, there is no difference between the contracts designed for him by the MI under propositions II and III.

Since the ultimate goal of the MI is to make money, the main question remaining to be asked is as follows: does being able to separate the Eneurs by their abilities work toward achieving the highest profit? To answer this question, I compare the profit obtained by the MI under the two considerations, i.e, when $\beta \in[0 ; 1[$ and when $\beta=1$. By comparing $\Pi_{P D}^{*}$, obtained when $\beta \in\left[0 ; 1\left[\right.\right.$, to $\Pi_{S D}^{*}$, when $\beta=1$, one can easily verify that the MI is better-off with the profits that stem from proposition II, i.e., $\Pi_{P D}^{*}$, than with the profits that stem from proposition III, i.e., $\Pi_{S D}^{*}$. Therefore, it is clear that, while knowing the Eneurs' abilities is a good thing for MIs, this does not allow them to achieve their foremost objectives i.e. reaping the highest possible profit from their investees. 


\section{Convertible Debt Contract}

The convertible debt contract proposed by the MI to the Eneur is a coupon $\gamma_{2}$ of the project yield he receives if it returns $X_{2}$, and a proportion $\gamma_{1}$ when he converts, i.e., if the project returns $X_{1}$. Since the essence of this paper is to find the appropriate financial claim, I assume that there is no partial conversion when the project returns $X_{1}$; i.e., either the MI converts the whole convertible debt or he does not.

Similarly to the equity and debt mechanisms, the MI's task is to solve the following problem:

$M A X \Pi_{\left(\gamma_{i 1}, \gamma_{i 2}\right)}=\eta\left\{\theta_{H} \gamma_{H 1} X_{1}+\left(1-\theta_{H}\right) \gamma_{H 2} X_{2}-K\right\}+(1-\eta)\left\{\theta_{L} \gamma_{L 1} X_{1}+\left(1-\theta_{L}\right) \gamma_{L 2} X_{2}-K\right\}$

subject to:

$$
\begin{aligned}
\theta_{H} X_{1}\left(1-\gamma_{H 1}\right)+\left(1-\theta_{H}\right)\left(1-\gamma_{H 2}\right) X_{2} & \left.\geq \theta_{H} X_{1}\left(1-\gamma_{L 1}\right)+\left(1-\theta_{H}\right)\left(1-\gamma_{L 2}\right) X_{2} 20\right) \\
\theta_{L} X_{1}\left(1-\gamma_{L 1}\right)+\left(1-\theta_{L}\right)\left(1-\gamma_{L 2}\right) X_{2} & \left.\geq \theta_{L} X_{1}\left(1-\gamma_{H 1}\right)+\left(1-\theta_{L}\right)\left(1-\gamma_{H 2}\right) X_{2} 21\right) \\
\theta_{H} X_{1}\left(1-\gamma_{H 1}\right)+\left(1-\theta_{H}\right)\left(1-\gamma_{H 2}\right) X_{2}-\psi_{H} & \geq 0 \\
\theta_{L} X_{1}\left(1-\gamma_{L 1}\right)+\left(1-\theta_{L}\right)\left(1-\gamma_{L 2}\right) X_{2}-\psi_{L} & \geq 0
\end{aligned}
$$

where $\gamma_{H 2}$ and $\gamma_{L 2}$ are the coupons paid by the L-type and H-type Eneurs, respectively, to the venture capitalist when the project returns $X_{2} \cdot \gamma_{L 1}$ and $\gamma_{H 1}$ are the L-type and H-type Eneurs' fractions of the project received by the MI when he converts. In this convertible debt contract, equation (19) stands for the MI's profit. Inequality (20) and inequality (21) are the high-ability and the low-ability Eneurs' self-selection constraints, respectively. Inequality (22) and inequality (23) are the individual rationality constraints for both types of Eneur, respectively.

\section{Proposition IV}

Under the convertible debt contract, the MI's optimal policy given by:

$$
\begin{gathered}
\gamma_{H 2}^{*}=\gamma_{L 2}^{*}=1 ; \\
\gamma_{L 1}^{*}=1-\frac{\psi_{L}}{\theta_{L} X_{1}} \\
\Pi_{P C D}^{*}=\eta\left(\theta_{H}-\theta_{L}\right)\left(X_{1}-X_{2}-\frac{\psi_{L}}{\theta_{L}}\right)+\left(V_{L}-\psi_{L}-K\right)
\end{gathered}
$$

Proof: see Appendix

$\gamma_{H 2}^{*}$ and $\gamma_{H 1}^{*}$ are obtained by maximizing equation (25), subject to inequality (26), to inequality (29) and $\Pi_{P C D}^{*}$ is the corresponding profit.

Like the equity contract, the convertible-debt device does not separate high-ability from low-ability Eneurs. As a result, if the MI's objective is to know the Eneur's ability 
to conduct the submitted project, his ultimate goal will not be achieved. Moreover, One would expect that convertible-debt, from its middle position between equity and debt, which should guarantee more intangible assets financing, would screen Eneurs by their abilities. However, proposition IV shows that it does not.

An interesting attribute of proposition IV is that the conditions under which the MI pools the Eneurs by type, is the same as in the debt contract. This result stems from the fact that, in the debt contract, $C_{H}=C_{L}=0$, and from the fact that, under the convertible-debt contract, $\gamma_{H 2}=\gamma_{L 2}=1$. As a result, it follows that whether the MI uses debt or convertible debt in one shot game, there is no difference between the profit received, even though the menus of both contracts are different.

\section{Choice of the Optimal Contract}

To select the suitable financial vehicle that allows the MI to attract more high-ability Eneurs and to achieve the highest profit I derive the optimal contract. To characterize the optimal contract, I compared the optimal value of $\eta$ under each contract to that of the others contracts and then compare the MI profit under the different contracts.

\section{$\underline{\text { Proposition V }}$}

The optimal financial vehicle for a monopolist financier,in nurturing a venture, is an equity contract since

$$
\begin{aligned}
\eta^{* * *} & =\eta^{* *}<\eta^{*} \text { where } \\
\eta^{*} & \left.=\frac{V_{L}-\psi_{L}-K}{\left(V_{L}-\psi-K\right)+\psi\left(\frac{V_{H}}{V_{L}}-1\right)} \quad \in\right] 0,1[\quad \text { and } \\
\eta^{* *} & \left.=\eta^{* * *} \frac{V_{L}-\psi-K}{\left(V_{H}-\psi-K\right)-\left(\theta_{H}-\theta_{L}\right)\left(X_{1}-X_{2}-\frac{\psi}{\theta_{L}}\right)} \quad \in\right] 0,1[ \\
& \text { and } \bullet \forall \eta \in\left[\eta^{* *}, \eta^{*}\right] \quad \Pi_{P D}^{*}=\Pi_{P C D}^{*}<\Pi_{P E}^{*}
\end{aligned}
$$

Proof see Appendix

Equation (26) in Proposition V shows that the equity contract attracts more highability Eneurs than the debt and convertible-debt contracts. The reason may be that only those Eneurs who know they are able to succeed will be inclined to give up part of their ventures in return for the MI's financial and management assistance. In addition, by becoming a shareholder, the MI will be more able to oversee the investee venture. Knowing this, the low-ability Eneur will be less attracted to the equity contract. In 
addition, equation (29) in proposition points out that the profit obtained by the MI under the equity contract is greater than that of the debt and convertible-debt contracts. Therefore, from proposition $\mathrm{V}$ it follows that it is in the MI best interest to use equity contract instead of a debt-linked contract.

To emphasize the dominance of the equity contract over that of debt and convertible debt I resort to the following two arguments. First, an investment in equity places the MI on the same level as the Eneur. As a result, the Eneur will view the MI as co-partner with whom he will seek the success of his venture. The intuition behind this argument is that the equity-mechanism design emphasizes the partnership relation between the MI and the Eneur and, thus, will probably reduce some agency problems that they will face in their contractual relation. Second, by using the equity mechanism, the venture capitalist will be able to manage their unsystematic risk exposure by working closely with the Eneur and management teams. This argument is based on the fact that, by holding a relatively substantial share of the Eneurial venture, the MI has a right to input in guiding that venture. Again, it should be noted that it is only by being a co-partner that the MI can behave in such manner.

\section{Welfare Analysis of the Incomplete Financial Con- tracts}

In this section, I delve into the comparative properties of the three financial contract menus to determine the best socially optimal one. For this purpose, the expected social welfare is defined as the sum of the expectations across types and states of the MI profit and the Eneur utility. More precisely, the expected social welfare is defined as the sum of the objectives of the MI and the high ability Eneur. Note that I do not have to worry about the social surplus derived from the low ability Eneur, since I know that I implement his first best solution in each incomplete financial contract.

Under the equity contract, the expected social welfare, ESW, is defined as:

$$
\begin{aligned}
E S W & =\Pi_{P E}^{*}+f\left(\phi_{P E}^{*}\right) \\
& =\eta\left[V_{H}-V_{L}-\psi\left(\frac{V_{H}}{V_{L}}-1\right)\right]+\left[V_{L}-\psi\left(\frac{V_{H}}{V_{L}}-2\right)-K\right]
\end{aligned}
$$

where $\Pi_{H E}=f\left(\phi_{P E}^{*}\right)$ is the profit derived by the high ability Eneur by concealing himself.

Under the collateral debt contract, the expected social welfare, DSW, is defined as: 


$$
\begin{aligned}
D S W & =\Pi_{P D}^{*}+g\left(\rho_{P D}^{*}\right) \\
& =\eta\left(\theta_{H}-\theta_{L}\right)\left(X_{1}-X_{2}\left(\frac{\psi}{\theta_{L}}-1\right)\right)+\left[V_{L}-\psi\left(\frac{\theta_{H}}{\theta_{L}}-2\right)-K\right]
\end{aligned}
$$

where $\Pi_{H D}=g\left(\rho_{P D}^{*}\right)$ is the profit derived by the high ability Eneur by concealing himself. Furthermore, since the pooling debt contract with collateral is equivalent to the convertible debt contract, it follows that under both contracts the expected social welfare is the same.

By comparing the expected social welfare under the different contract, I can clearly identify which contract contributes more the general social welfare. To do so, I compute the difference, the following difference, ESW- DSW, between the welfare under the equity contract and the welfare under the debt instruments contracts.

\section{$\underline{\text { Proposition VI }}$}

Ceteris paribus, the equity contract generates more social welfare than the debtlinked contract.

$E S W-D S W=\eta\left\{\left[V_{H}-V_{L}-\psi\left(\frac{V_{H}}{V_{L}}-1\right)\right]-\left(\theta_{H}-\theta_{L}\right)\left(X_{1}-X_{2}-\frac{\psi}{\theta_{L}}\right)\right\}+\psi\left(\frac{V_{H}}{V_{L}}-\frac{\theta_{H}}{\theta_{L}}\right)>0$

$\underline{\text { proof }}$

For all $\eta$ greater than zero, it is easy to see that the first part of the right hand side of equation (34) is positive. Moreover, for all $\psi$, the second part of the right hand side of equation (34) is positive. Therefore, it follows that the sign of right hand side of equation (34) is positive, suggesting that, with asymmetrical information under the monopoly market structure, the social welfare under equity capital structure exceed that under the debt financial instrument.

This result reinforces the conclusions I drew from the section D namely Choice of the Optimal Contract. Put in another way, the welfare analysis has indicated that the MI should use common share to design an incomplete financial contract to the Eneur. This, in order to fully play his role which ultimate purpose his to increase the social welfare. It is only by using this financial vehicle that a MI can act as a sounding board for management, to provide links to the financial community, and to share their business acumen. In addition, it only by nurturing his investee with the equity that he can bring with him myriad experiences of success and failure to share the lessons of those experiences with his new investees. 


\section{Conclusion}

This paper analyzes the one period problem that a monopoly faces in designing an incentive compatible contract to Eneur, namely, what is the appropriate financial instrument to nurture his investees in an adverse selection context. I have shown here that neither equity nor debt-linked contract are not able to screen out the high ability Eneur from low ability Eneur. Therefore, in one shot investment game, the financial instrument used to design the contract is not helpful to achieve the desire separating equilibrium.

I also prove that, depending on the disparity factor of the valuation of the collateral in the debt contract, the debt mechanism could achieve a pooling or separating equilibrium. However, for the venture capitalist's own best interest, we show that the pooling contract dominates the separating contract. In this pooling contract, I show that the collateral is not valuable. As a result, it follows that collateral does not play a useful role in making the loan riskless, and in discouraging the low-ability entrepreneur from applying for capital.

Furthermore, I have demonstrated the equity contract dominates the debt-linked contracts in the sense that it serves the the MI best interest because the profits it generates are higher than the profits derived from the collateral debt and convertible debt contract. In addition, I have proven that the social welfare that results from the equity contract is higher that the social welfare that the debt-linked contract provide. Therefore socially the equity contract is better than the debt-linked contract

My model can be extended in a variety of directions. In multi-period game it would be interesting to build and test the following pecking order financial contract that probably fit a MI relation with Eneur in term of asymmetrical information and uncertainty resolution. Contrary to Myers and Majluf (1984) the pecking order will be as follows. Common stock will be used first, then convertible security and finally debt. A related and important theoretical and regulation question is to analyze the mechanisms that will allow a MI such as World Bank, IFM and the big monopoly that uniquely designed debt contracts to their third world investees to begin to use equity contract that will allow them to play a full partner role in nurturing their investees. 


\section{Appendixes}

\section{A Proof of proposition I}

In solving the MI's problem, I primarily ignore the low-ability Eneur incentive-compatibility constraint and the high-ability Eneur participation constraint. In this less constrained problem, I optimize with respect to $\phi_{H}$ and $\phi_{L}$. Having solved the less constrained problem, I show that this solution indeed satisfies the low-ability Eneur incentivecompatibility constraint and the high-ability Eneur participation constraint.

The Lagrangian for the less-constrained problem is:

$$
\begin{aligned}
L= & \eta\left(\phi_{H} V_{H}-K\right)+(1-\eta)\left(\phi_{L} V_{L}-K\right) \\
& +\mu\left\{\left(1-\phi_{H}\right) V_{H}-\left(1-\phi_{L}\right) V_{H}\right\} \\
& +\lambda\left\{\left(1-\phi_{L}\right) V_{L}-\psi\right\}
\end{aligned}
$$

where $\mu$ and $\lambda$ stand respectively for the Lagrangian multipliers for the high-ability Eneur incentive-compatibility constraint and the low-ability Eneur participation constraint.

The first order condition for $\phi_{H}$ and $\phi_{L}$ yields the following implications:

$$
\begin{aligned}
\partial L / \partial \phi_{H} & =\eta V_{H}-\mu V_{H}=0 \Longrightarrow \mu=\eta \\
\partial L / \partial \phi_{L} & =(1-\eta) V_{L}+\mu V_{H}-\lambda V_{L}=0 \Longrightarrow \lambda=(1-\eta)+\eta \frac{V_{H}}{V_{L}}
\end{aligned}
$$

Conditions (B4) and (B5) imply that $\mu>0$ and $\lambda>0$. Thus the high-ability Eneur incentive-compatibility constraint and the low-ability Eneur participation constraint are tied up.

From the low-ability Eneur participation constraint I have:

$$
\begin{aligned}
\left(1-\phi_{L}\right) V_{L}-\psi & =0 \\
\phi_{L} & =\phi_{P}^{*}=1-\frac{\psi}{V_{L}}
\end{aligned}
$$

From the high-ability Eneur incentive-compatibility constraint I have:

$$
\begin{aligned}
\left(1-\phi_{H}\right) V_{H}-\left(1-\phi_{L}\right) V_{H} & =0 \\
V_{H}\left(\phi_{L}-\phi_{H}\right) & =0
\end{aligned}
$$

Since $\theta_{H} V_{H}>0$, it follows that: $\phi_{H}=\phi_{L}=\phi_{P E}^{*}$ 
To verify that the solution to the less constrained problem satisfies the low-ability Eneur incentive constraint, note that:

$$
\left(1-\phi_{L}\right) V_{L}-\left(1-\phi_{H}\right) V_{L}=0
$$

since $\phi_{H}=\phi_{L}=\phi_{P E}^{*}$.

To verify that the high-ability Eneur participation constraint is satisfied, note that:

$$
\begin{aligned}
\left(1-\phi_{H}\right) V_{H}-\psi & =\left(1-1+\frac{\psi}{V_{L}}\right) V_{H}-\psi \\
& =\psi\left(\frac{V_{H}}{V_{L}}-1\right)>0
\end{aligned}
$$

since $\frac{V_{H}}{V_{L}}>1$ because $V_{H}>V_{L}$

To have the corresponding profit to the pooling contract, I substitute $\phi_{P}^{*}=1-\frac{\psi}{V_{L}}$ into $\Pi=\eta\left(\phi_{H} V_{H}-K\right)+(1-\eta)\left(\phi_{L} V_{L}-K\right)$. After some algebraic manipulations, I get:

$$
\Pi_{P E}^{*}=\eta\left[V_{H}-V_{L}+\psi\left(1-\frac{V_{H}}{V_{L}}\right)\right]+\left(V_{L}-\psi-K\right)
$$

As for the pooling contract, by substituting $\phi_{H}^{*}=1-\frac{\psi}{V_{H}}$ into $\Pi_{H}=\eta\left(\phi_{H} V_{H}-K\right)$, I get

$$
\Pi_{H E}^{*}=\eta\left(V_{H}-\psi-K\right)
$$

\section{B Proof of proposition II}

In solving the MI's debt-contract problem, I ignore the low- ability Eneur incentivecompatibility constraint and the high-ability Eneur individual-rationality constraint. As in the equity contract, I will resolve the MI's optimization problem, subject to the highability Eneur incentive-compatibility constraint and the low-ability Eneur individualrationality constraint. Having solved the less constrained problem, I show that the solution satisfies both of the constraints that I ignored.

The Lagrangian for this less constrained problem can be expressed as:

$$
\begin{aligned}
L= & \eta\left[\theta_{H} \rho_{H}+\left(1-\theta_{H}\right)\left(X_{2}+\beta C_{H}\right)-K\right]+(1-\eta)\left[\theta_{L} \rho_{L}+\left(1-\theta_{L}\right)\left(X_{2}+\beta C_{L}\right)-K\right]( \\
& +\mu\left\{\theta_{H}\left(X_{1}-\rho_{H}\right)-\left(1-\theta_{H}\right) C_{H}-\theta_{H}\left(X_{1}-\rho_{L}\right)+\left(1-\theta_{H}\right) C_{L}\right\} \\
& +\lambda\left\{\theta_{L}\left(X_{1}-\rho_{L}\right)-\left(1-\theta_{L}\right) C_{L}\right\}+\psi+\tau_{1} C_{L}+\tau_{2} C_{H}
\end{aligned}
$$


where $\mu$ stands for the Lagrangian multiplier for the high-ability Eneur incentivecompatibility and $\lambda$ stands for the multiplier for low-ability participation constraint. The Lagrangian multipliers $\tau_{1}$ and $\tau_{2}$ are the multipliers for the non-negativity constraints on $C_{i}$ for $i=L, H$.

The first order condition for $\rho_{i}$ and $C_{i}$ for $i=H, L$ gives:

$$
\begin{aligned}
\partial L / \partial \rho_{H}= & \eta \theta_{H}-\mu \theta_{H}=0 \Longrightarrow \mu=\eta \\
\partial L / \partial C_{H}= & \eta\left(1-\theta_{H}\right) \beta-\mu\left(1-\theta_{H}\right)+\tau_{2}=0 \Longrightarrow \tau_{2}=\eta\left(1-\theta_{H}\right)(1-\beta) \\
\partial L / \partial \rho_{L}= & (1-\eta) \theta_{L}+\mu \theta_{H}-\lambda \theta_{L}=0 \Longrightarrow \lambda=(1-\eta)+\eta \theta_{H} \theta_{L}^{-1} \\
\partial L / \partial C_{L}= & (1-\eta)\left(1-\theta_{L}\right) \beta+\mu\left(1-\theta_{H}\right)-\lambda\left(1-\theta_{L}\right)+\tau_{1}=0 \\
& \Longrightarrow \tau_{1}=\left(1-\theta_{L}\right)(1-\eta)(1-\beta)+\eta\left[\left(1-\theta_{L}\right) \theta_{H} \theta_{L}^{-1}-\left(1-\theta_{H}\right)\right]
\end{aligned}
$$

Condition (C19) implies that $\tau_{2}>0$.

In condition $(\mathrm{C} 22)$ I have: $\left(1-\theta_{L}\right)>\left(1-\theta_{H}\right)$ and $\frac{\theta_{H}}{\theta_{L}}>1 \Longrightarrow\left(1-\theta_{L}\right) \frac{\theta_{H}}{\theta_{L}}>\left(1-\theta_{H}\right)$. Thus, it follows that condition $(\mathrm{C} 22)$ implies that $\tau_{1}>0$.

Since $\tau_{1}>0$ and $\tau_{2}>0$; it follows that:

$$
C_{H}^{*}=C_{L}^{*}=0
$$

Condition (C20) implies that the low-ability Eneur individual-rationality constraint is binding. So, since $C_{L}^{*}=0$

$$
\begin{aligned}
\theta_{L}\left(X_{1}-\rho_{L}\right)-\left(1-\theta_{L}\right)\left(X_{2}+C_{L}\right)-\psi & =0 \\
\theta_{L} X_{1}-\theta_{L} \rho_{L}-\psi & =0 \\
\rho_{L}^{*} & =X_{1}-\frac{\psi}{\theta_{L}}
\end{aligned}
$$

Condition (C22) implies that the high-ability Eneur incentive-compatibility constraint is binding. Thus, since $C_{H}^{*}=C_{L}^{*}=0$ and $\mu=\eta$, I have:

$$
\begin{aligned}
\theta_{H}\left(X_{1}-\rho_{H}\right)-\left(1-\theta_{H}\right) C_{H}-\theta_{H}\left(X_{1}-\rho_{L}\right)+\left(1-\theta_{H}\right) C_{L} & =0 \\
\theta_{H}\left[\left(X_{1}-\rho_{H}\right)-\left(X_{1}-\rho_{L}\right)\right] & =0 \\
\rho_{P D}^{*} & =X_{1}-\frac{\psi}{\theta_{L}}
\end{aligned}
$$


where $\rho_{P D}^{*}=\rho_{H}^{*}=\rho_{L}^{*}$

To prove that the solution for the less constrained problem holds for the low-ability Eneur incentive-compatibility constraint, note that:

$$
\theta_{L}\left(X_{1}-\rho_{L}^{*}\right)-\left(1-\theta_{L}\right) C_{L}^{*}-\theta_{L}\left(X_{1}-\rho_{H}^{*}\right)+\left(1-\theta_{L}\right) C_{H}^{*}=0
$$

To prove that the high-ability Eneur individual-rationality constraint holds for the solution for the less constrained problem, note that:

$$
\begin{aligned}
\theta_{H}\left(X_{1}-\rho_{H}^{*}\right)-\left(1-\theta_{H}\right) C_{H}^{*}-\psi & =\theta_{H} X_{1}-\theta_{H}\left(X_{1}-\frac{\psi}{\theta_{L}}\right)-\psi \\
& =\psi\left(\frac{\theta_{H}}{\theta_{L}}-1\right)>0
\end{aligned}
$$

since $\frac{\theta_{H}}{\theta_{L}}>1$ because $\theta_{H}>\theta_{L}$

To have the corresponding profit for the pooling contract, I substitute: $C_{H}^{*}=C_{L}^{*}=0$ and $\rho_{H}^{*}=\rho_{L}^{*}=X_{1}-\frac{\psi}{\theta_{L}}$ in

$$
\Pi=\eta\left[\theta_{H} \rho_{H}+\left(1-\theta_{H}\right)\left(X_{2}+\beta C_{H}\right)-K\right]+(1-\eta)\left[\theta_{L} \rho_{L}+\left(1-\theta_{L}\right)\left(X_{2}+\beta C_{L}\right)-K\right]
$$

I get, after algebraic manipulations:

$$
\Pi_{P D}^{*}=\eta\left(\theta_{H}-\theta_{L}\right)\left(X_{1}-X_{2}-\frac{\psi}{\theta_{L}}\right)+\left(V_{L}-\psi-K\right)
$$

As for the profit that the MI receives when just financing the high-ability Eneur, I get, by substituting $C_{H}=0$ and $\rho^{*}=X_{1}-\frac{\psi}{\theta_{H}}$

$$
\Pi_{H D}^{*}=\eta\left(V_{H}-\psi-K\right)
$$

\section{Proof of proposition III}

From $(\mathrm{C} 19))$ it is straightforward to verify that by setting $\beta=1, \tau_{2}=0$. As a result, it follows that $C_{H}^{*}>0$.

From (C22), it is also straightforward to check that $\tau_{1}>0$ for $\beta=1$. Therefore, it follows that $C_{L}^{*}=0$

Since from (C20) I do know that $\lambda>0$, it follows that the low-type Eneur individualrationality constraint is tied up. In this respect, one can easily check, after some algebraic manipulations, that:

$$
\rho_{L}^{*}=X_{1}-\frac{\psi}{\theta_{L}} \quad \text { for } \quad C_{L}^{*}
$$


From (C18), I know that $\mu=\eta>0$. From this, it follows that the incentive compatibility constraint of the high-ability Eneur is tied up. Now, by substituting $C_{L}^{*}=0$ in the high-ability Eneur incentive compatibility and by performing the appropriate algebraic manipulations, it is straightforward to obtain:

$$
\rho_{H}^{*}=\rho_{L}^{*}-\frac{1-\theta_{H}}{\theta_{H}} C_{H}^{*}
$$

\section{Proof of proposition IV}

The proof of the proposition IV is constructive. In solving the MI's convertible-debtcontract problem, I first ignore the low-ability Eneur self-selection constraint and the high-ability Eneur participation constraint. Thus, I maximize the MI's profit, subject to the high-ability Eneur self-selection constraint and the low-ability Eneur participation constraint. Having solved the less constrained problem, I show that the solution satisfies both of the constraints that I ignored.

Like other linear programming problems, the optimal solutions of the convertibledebt contract occur at vertices of the region of feasible solutions. As a result, the optimal solution is the corner point that yields the optimal value for the objective function. This linear programming problem lends itself to some specific considerations. First, I rule out the solution $\gamma_{H 1}=\gamma_{L 1}=1$ because it is unthinkable that, in case of success, the Eneur entirely gives up the venture to the MI, whatever his type. Second, I rule out the solution $\gamma_{H 1}=\gamma_{L 1}=0$ because it is in case of success that the MI is compensated for his financial and management involvement in this investee firm. Third, I rule out the possibility that $\gamma_{H 2}=\gamma_{L 2}=0$ because when the project returns $X_{2}$, i.e., fails, it is well- known that any financier like the MI receives all the proceeds of the project to partly compensate his investment. According to this, and without loss of generality, $\gamma_{H 2}=\gamma_{L 2}=1$ when $X_{2}<K$.

The less constrained problem solved by the MI is expressed as follows:

$$
\operatorname{Max} \Pi_{\left(\gamma_{i 1}, \gamma_{i 2}\right)}=\eta\left\{\theta_{H} \gamma_{H 1} X_{1}+\left(1-\theta_{H}\right) \gamma_{H 2} X_{2}-K\right\}+(1-\eta)\left\{\theta_{L} \gamma_{L 1} X_{1}+\left(1-\theta_{L}\right) \gamma_{L 2} X_{2}-K\right\}
$$

subject to:

$$
\begin{array}{r}
\theta_{H} X_{1}\left(1-\gamma_{H 1}\right)+\left(1-\theta_{H}\right)\left(1-\gamma_{H 2}\right) X_{2} \geq \theta_{H} X_{1}\left(1-\gamma_{L 1}\right)+\left(1-\theta_{H}\right)\left(1-\gamma_{L 2}\right) X_{2}(\mathrm{D} 37) \\
\theta_{L} X_{1}\left(1-\gamma_{L 1}\right)+\left(1-\theta_{L}\right)\left(1-\gamma_{L 2}\right) X_{2}-\psi \geq 0
\end{array}
$$

Knowing that $\gamma_{L 2}^{*}=1$, substituting $\gamma_{L 2}$ in the low-ability Eneur participation constraint, and solving for $\gamma_{L 1}$ in this constraint, I get: 


$$
\gamma_{L 1}^{*}=1-\frac{\psi}{\theta_{L} X_{1}}
$$

Substituting $\gamma_{H 2}^{*}=\gamma_{L 2}^{*}=1$ and $\gamma_{L 1}^{*}$ by their respective values in the high-ability Eneur self-selection constraint I obtain, after some algebraic manipulation:

$$
\gamma_{H 1}^{*}=\gamma_{L 1}^{*}=1-\frac{\psi}{\theta_{L} X_{1}}
$$

It remains to show that the solution to the less constrained problem I solve does not violate the two constraints I ignore. First, to verify that the solution to the less constrained problem satistifies the low-ability Eneur self-selection constraint, note that:

$$
\theta_{L} X_{1}\left(\gamma_{H 1}^{*}-\gamma_{L 1}^{*}\right)+\left(1-\theta_{L}\right)\left(\gamma_{H 2}^{*}-\gamma_{L 2}^{*}\right) X_{2}=0
$$

Second, to verify that the less constrained problem satisfies the high-ability Eneur participation constraint note that:

$$
\begin{gathered}
-\theta_{H} X_{1}\left(1-\frac{\psi}{\theta_{L} X_{1}}\right)-\left(1-\theta_{H}\right) X_{2} \succ \psi-\theta_{H} X_{1}-\left(1-\theta_{H}\right) X_{2} \\
\psi\left(\frac{\theta_{H}}{\theta_{L}}-1\right)>0
\end{gathered}
$$

since $\frac{\theta_{H}}{\theta_{L}} 1$ because $\theta_{H}>\theta_{L}$.

To obtain the MI's optimal profit, which corresponds to $\gamma_{H 2}^{*}=\gamma_{L 2}^{*}$ and $\gamma_{H 1}^{*}=$ $\gamma_{L 1}^{*}$, I substitute in his profit expression these optimal values. After some algebraic manipulations I get the optimal profit:

$$
\Pi_{P C D}^{*}=\eta\left(\theta_{H}-\theta_{L}\right)\left(X_{1}-X_{2}-\frac{\psi}{\theta_{L}}\right)+\left(V_{L}-\psi-K\right)
$$

To obtain the MI's profit when he just finances the H-type Eneur, I substitute in the corresponding profit expression $\gamma_{L 2}^{*}=1$ and $\gamma_{H 1}^{*}=1-\frac{\psi}{\theta_{L} X_{1}}$. After some algebraic manipulation I get:

$$
\Pi_{H C D}^{*}=\eta\left(V_{H}-\psi-K\right)
$$

\section{E Proof of proposition V}

$\underline{\text { Derivation of } \eta^{*}}$ 
Let momentarily assume that the the MI can just finance the high-ability Eneur. The proportion of the venture he will require $\phi_{H E}^{*}$, and the corresponding profit $\Pi_{H E}^{*}$ are.

$$
\begin{gathered}
\phi_{H E}^{*}=1-\frac{\psi}{V_{H}} \\
\Pi_{H E}^{*}=\eta\left(V_{H}-\psi-K\right)
\end{gathered}
$$

Knowing the value of $\phi_{H E}^{*}, \phi_{P E}^{*}$ and the value of $\Pi_{H E}^{*}, \Pi_{P E}^{*}$; I derive then derive $\eta^{*}$ as the required proportion of the high-ability Eneurs for which the MI is indifference between offering a pooling contract or just financing the high-ability Eneur.

$$
\left.\eta^{*}=\frac{V_{L}-\psi-K}{\left(V_{L}-\psi-K\right)+\psi\left(\frac{V_{H}}{V_{L}}-1\right)} \quad \in\right] 0,1[
$$

is obtained by equalizing $\Pi_{P E}^{*}=\Pi_{H E}^{*}$ and by performing the appropriate algebraic manipulations.

Derivation of $\eta^{*} *$ and $\eta^{*} * *$

To derive $\eta^{*} *$ and $\eta^{*} * *$ I follow the same procedure like for $\eta^{*}$ and performing the appropriate algegraic manipulations. Having done that I obtain $\eta^{*} *$ and $\eta^{*} *$; and have found that $\eta^{*} *=\eta^{*} *$.

$$
\left.\eta^{* *}=\eta^{* * *} \frac{V_{L}-\psi-K}{\left(V_{H}-\psi-K\right)-\left(\theta_{H}-\theta_{L}\right)\left(X_{1}-X_{2}-\frac{\psi}{\theta_{L}}\right)} \quad \in\right] 0,1[
$$

- $\quad \eta^{* * *}=\eta^{* *}<\eta^{*}$

From the denominator of the expression of $\eta^{* *}$ or $\eta^{* * *}$, i.e., the denominator of equation (21) or equation (34) and from the denominator of the expression of $\eta^{*}$, i.e., equation (10), one can easily verify that:

$$
\begin{gathered}
\left(\theta_{H}-\theta_{L}\right)\left(X_{1}-X_{2}-\frac{\psi}{\theta_{L}}\right)<V_{L}-\psi-K \prec V_{H}-\psi-K \\
V_{L}-\psi-K<\left(V_{H}-\psi-K\right)-\left(\theta_{H}-\theta_{L}\right)\left(X_{1}-X_{2}-\frac{\psi}{\theta_{L}}\right) \\
\psi\left(\frac{V_{H}}{V_{L}}-1\right)<\left(\theta_{H}-\theta_{l}\right)\left(X_{1}-X_{2}-\frac{\psi}{\theta_{L}}\right)
\end{gathered}
$$

Now, from (F46), (F47) and (F48) it follows that the denominator of $\eta^{* * *}=\eta^{* *}$ is inferior to the denominator of $\eta^{*}$ i.e.:

$$
\left.\left(V_{L}-\psi-K\right)+\psi\left(\frac{V_{H}}{V_{L}}-1\right)<\left(V_{H}-\psi-K\right)-\theta_{H}-\theta_{l}\right)\left(X_{1}-X_{2}-\frac{\psi}{\theta_{L}}\right)
$$


Having shown that the denominator of $\eta^{* *}$ is inferior to the denominator of $\eta^{*}$, I can easily show that inequality (35) in proposition $\mathrm{V}$ holds. To see this, first note that the numerator of equation (10) is equal to the numerator of equation (21). Second, note that the denominator of equation (10) is inferior to the denominator of equation (21) as I have just shown it. Therefore, it is straightforward to see that $\eta^{* * *}=\eta^{* *}<\eta^{*}$, i.e., inequality (35) in proposition $\mathrm{V}$ holds.

\section{Proof of Corrolary I}

Denote $\Pi_{H}^{*}$ the profit obtained by the MI if can just finance the high-ability Eneur.One can easily checked that whatever the financial intrument used by the MI to design an incentive contract to the high-ability Eneur, he end up by having the same profit. As a result, it follows that: $\Pi_{H}^{*}=\Pi_{H E}^{*}=\Pi_{H D}^{*}=\Pi_{H C D}^{*}$ as stated in equation(A14)

From proposition II and proposition IV, I know that:

$$
\forall \eta>\eta^{* *}: \Pi_{P D}^{*}=\Pi_{P C D}^{*}<\Pi_{H}^{*}
$$

Moreover, from proposition I, I know that:

$$
\forall \eta<\eta^{*}: \Pi_{P E}^{*} \geq \Pi_{H}^{*}
$$

From (F52) and (F57), it follows that:

$$
\forall \eta \in\left[\eta^{* *}, \quad \eta^{*}\right] \Pi_{P D}^{*}=\Pi_{P D C}^{*}<\Pi_{P E}^{*}
$$

\section{References}

[1] R. A. Haugen A. Barnea and L. W. Senbet. Agency Problems and Financial Contracting. Prentice-Hall, Inc., 1985.

[2] A. R. Adamati and P. Pfleiderer. Robust financial contracting and the role of venture capitalists. Journal of Finance, 7:371-402, 1994.

[3] G. Akerlof. The market for lemons: qualitative uncertainty and the market mechanism. Quaterly Journal of Economics, 84:488-500, 1970.

[4] A. Amit, L. Glosten, and E. Muller. Entrepreneurial ability, venture investments, and risk sharing. Management Science, 36:1232-1245, 1990.

[5] Bascha Andreas and Uwe Walz. Convertible securities and optimal exit decisions in venture capital financ2. journal of Corporate Finance, 7:285-306, 2001.

[6] D. Besanko and A. V. Thakor. Collateral and rationing: Sorting equilibria in monopolistic and competitive credit markets. International Economic Review, 28 no 3:671-689, 1987. 
[7] H. Bester. Screnning, vs rationing in credit markets with imperfect information. American Economic Review, 57:850-55, 1985.

[8] Casamatta C. Financing and advising: Optimal financial contracts with venture capitalists. University of Tolouse, Working paper, 1999.

[9] Bergemann Dirk and Ulrich Hege. Venture capital financing, moral hazard, and learning. Journal of BankingEFFinance, 22:703-735, 1998.

[10] Z. Fluck. Optimal financial contracting: Debt versus outside equity. Review of Financial Studies, 11(2):384-418, 1998.

[11] X. Freixa and J.J Laffont. Optimal banking contract. In P. Champsaur et al. Cambridge, editor, Essays in Honor of Edmond Malinvaud, Vol.2, Macroeconomics. MIT Press, 1990.

[12] M. Gorman and W. A. Sahlman. What do venture capitalists do? Journal of Business Venturing, 4:231-248, 1989.

[13] M. Harris and A. Raviv. The theory of capital structure. Journal of Finance, 46:297-355, 1991.

[14] M. Harris and A. Raviv. Financial contracting theory. In J.J Laffont, editor, Advances in Economic Theory: sixth World Congress, Vol.2, Econometric Society Monographs no.21 Cambridge, 64-150. 1992.

[15] O. Hart. Firms Contracts and Financial Structure. Oxford University Press, 1995.

[16] M. C. Jensen and W. Meckling. Theory of firm: managerial behavior, agency costs and capital structure. Journal of Financial Economics, pages 305-360, 1976.

[17] E. Hayne Leland and H. David Pyle. Informational asymmetries, financial structure, and financial intermediation. Journal of Finance, 32, no.2:371-87, 1977.

[18] S. C. Myers and N. S. Majluf. Corporate financing and investment decisions when firms have informations that investors do not have. Journal of Financial Economics, pages 187-221, 1984.

[19] R. Myerson. Incentive compatibility and the bargaining problem. Econometrica, 47(1):6173, 1979.

[20] B. Salanié. The Economics of Contracts A primer. The MIT Press, 1997.

[21] K. Schmidt. Convertible securities and venture capital finance. CEPR Discussion Paper, No. 2317, 2000.

[22] A. J. Timmons. New Venture Creation. Irwin-McGraw-Hill, 1994.

[23] D. C. Webb. Long term financial contracts can mitigate the adverse selection problem in project financing. International Economic Review, 32(2):305-20, 1991. 